John Carroll University

Carroll Collected

2020

Support for the habitat amount hypothesis from a global synthesis of species density studies

James I. Watling

Rebecca Fang

Follow this and additional works at: https://collected.jcu.edu/fac_bib_2020

Part of the Biology Commons, and the Mathematics Commons 


\title{
Support for the habitat amount hypothesis from a global synthesis of species density studies
}

\begin{abstract}
Decades of research suggest that species richness depends on spatial characteristics of habitat patches, especially their size and isolation. In contrast, the habitat amount hypothesis predicts that (1) species richness in plots of fixed size (species density) is more strongly and positively related to the amount of habitat around the plot than to patch size or isolation; (2) habitat amount better predicts species density than patch size and isolation combined, (3) there is no effect of habitat fragmentation per se on species density and (4) patch size and isolation effects do not become stronger with declining habitat amount. Data on eight taxonomic groups from 35 studies around the world support these predictions. Conserving species density requires minimising habitat loss, irrespective of the configuration of the patches in which that habitat is contained.
\end{abstract}

Keywords

Forest loss, habitat amount, patch size, sampling effect.

\section{INTRODUCTION}

Rapid agricultural expansion has converted vast areas of natural vegetation to farmland, leaving remaining natural cover fragmented into numerous patches (Barnosky et al. 2012; Taubert et al. 2018). Decades of work have demonstrated that small patches contain fewer species than large patches (Watling \& Donnelly 2006; Matthews et al. 2016). Consequently, conservation strategies generally prioritise the preservation of large contiguous areas of natural vegetation cover, while small patches receive little or no protection. The habitat amount hypothesis (HAH) challenges the assumption that small patches have little biodiversity value. The hypothesis states that species density, the number of species in a plot of fixed size, increases with total habitat area in the 'local landscape' surrounding the plot (Fahrig 2013). The local landscape defines the distance within which individuals are likely to arrive in the plot (the 'scale of effect'; Martin \& Fahrig 2012). The HAH predicts that the size of the patch in which a plot is located has little additional effect on species density beyond its contribution to habitat amount in the local landscape (Fahrig 2013). To illustrate, consider a plot located in a large patch surrounded by little additional habitat in the local landscape (Fig. 1a). Then consider a plot in a smaller patch surrounded by additional habitat (Fig. 1b). The HAH suggests that species density is equivalent in both cases, as long as total habitat amount in the two local landscapes is the same. Similarly, the HAH predicts that species density will be equivalent in Fig. 1c,d, although lower in both cases compared with the high habitat amount landscapes in Fig. 1a,b. Where all the habitat in the local landscape occurs as a single patch, the effects of habitat amount and patch size on species density are equivalent. If supported, the HAH would suggest that conservation activities should focus on preserving and restoring as 
much habitat as possible. In areas of continuous habitat, this means preventing habitat loss in the first place. In fragmented landscapes, support for the HAH highlights the conservation value of all patches, large and small, for habitat maintenance.

In addition to patch size effects, a large body of literature has documented negative effects of patch isolation on species richness (reviewed in Watling \& Donnelly 2006; Weigelt \& Kreft 2013). There are two main types of isolation measures: area-based and distance-based (Prugh 2009), with some hybrid measures that include both area and isolation (e.g. the incidence function model; Hanski 1994). If we consider a sample plot within a patch, area-based isolation measures sum the area of the patch within which a plot is located (or the portion of that patch within the local landscape) plus any additional habitat in the local landscape. The main prediction of the $\mathrm{HAH}$ is that the relationship between species density in a plot and habitat amount in its local landscape is identical to the relationship between species density and the combined effects of the size and isolation of the patch containing that plot, when isolation is measured as the inverse of the amount of habitat surrounding the patch (and if the whole patch is contained in the local landscape). If a distance-based patch isolation measure is used, then the $\mathrm{HAH}$ predicts that the effect of habitat amount on species density will be stronger than the combined effects of patch size and patch isolation. This is because the correlation between distance-based
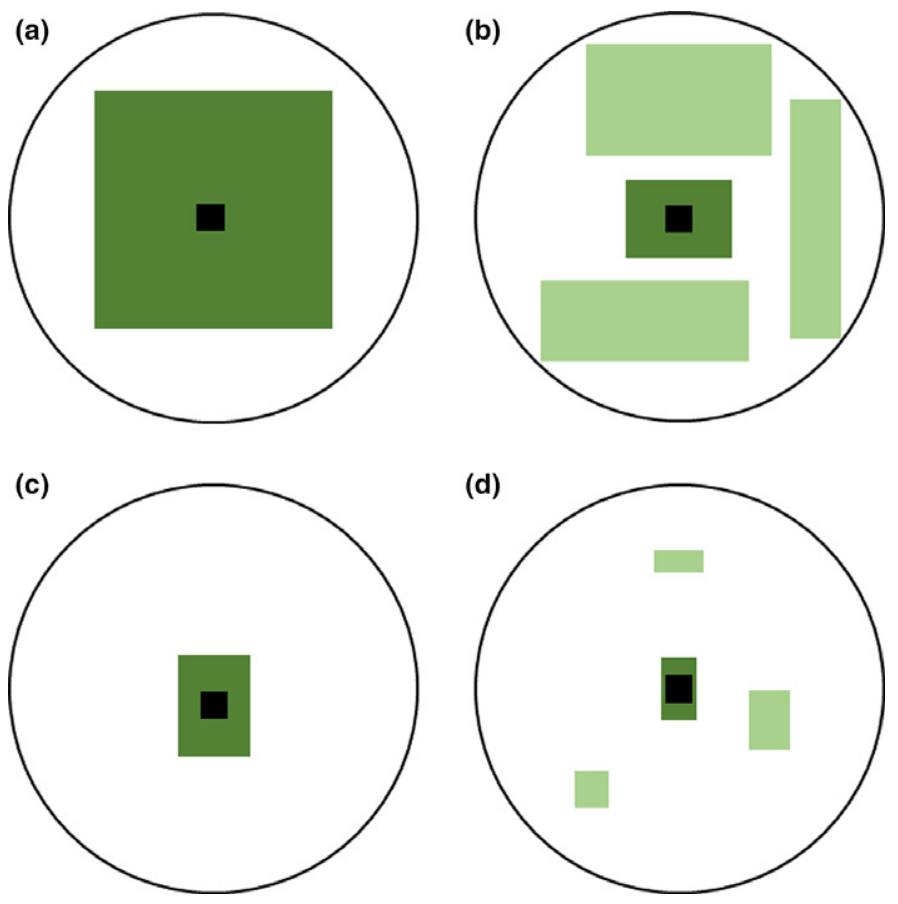

Figure 1 The habitat amount hypothesis predicts that species richness in equally sized sample plots (species density; black squares) is determined by the total habitat area (all green polygons) in a local landscape (large circles), rather than the size of the local patch in which plots are located (dark green polygons). According to the habitat amount hypothesis, species density should be the same in sample plots in landscapes (a) and (b), or (c) and (d). When the local patch occupies all of the habitat in a local landscapes (a or c), local patch size and habitat amount effects are equivalent, whereas in landscapes (b) and (d), the number of species in sample plots is expected to be more related to habitat amount than to patch size. isolation and habitat amount is weaker than the correlation between area-based isolation metrics and habitat amount. In short, the HAH predicts that species density in a plot is influenced by the amount of habitat surrounding the plot, not whether that habitat occurs within the patch containing the plot (the local patch), or elsewhere in its local landscape. By extension, the $\mathrm{HAH}$ predicts no effect of fragmentation per se (i.e. controlling for habitat amount) on species density in plots. Note that we define fragmentation as a spatial pattern in which habitat is comprised of multiple, isolated patches (Fahrig et al. 2019), rather than the process of habitat loss, subdivision and other activities such as hunting that often erode biodiversity (Lindenmayer \& Fischer 2007).

The HAH does not deny that the effects of patch characteristics such as size and shape may depend on attributes of the surrounding landscape. For example, species composition in relatively small forest fragments in high forest cover landscapes may be more similar to large fragments than they are to small fragments in landscapes with little forest cover (Banks-Leite et al. 2012). However, the HAH does not predict stronger effects of patch size, isolation or fragmentation per se with declining habitat amount. Because habitat amount is defined at the scale of effect for a given taxon, all habitat within the local landscape is available to individuals, regardless of the number of patches or nearest-neighbour distances characterising that habitat. Furthermore, the HAH states that the effect of patch size on species density in plots contained in that patch is entirely due to the contribution of that patch to the total habitat amount in the local landscape. Therefore, the relative importance of local patch size (the patch in which a sample plot is located) will depend on the contribution of that patch to habitat amount in the local landscape. When most of the habitat in a local landscape is comprised of a single local patch, the effect of patch size on species density is large. But when the local patch contains little of the habitat in the local landscape, the effect of patch size decreases, regardless of habitat amount.

If supported, the HAH would serve as a null model for the relationship between species density in plots and habitat distribution. The HAH has been criticised for invoking passive sampling as its basis (Hanski 2015; Haddad et al. 2017) because previous work has identified various mechanisms to explain species declines in response to decreasing patch size and habitat subdivision (e.g. negative edge effects; Pfeifer et al. 2017). Rather than being a limitation, we view the parsimony of the HAH as a strength. Replacing patch area and isolation effects with a single measure of habitat amount would provide a useful approximation for describing the key landscape driver of species density in sample plots.

Early tests of the HAH have been inconsistent, with some studies supporting the hypothesis (Melo et al. 2017), some refuting it (Haddad et al. 2017; Saldhana Bueno \& Peres 2019), and others providing partial support (Martin 2018; Viera et al. 2018). The strongest tests of the HAH will (1) be conducted at the plot rather than patch scale, to control for sampling intensity and (2) if conducted at the patch scale, they will include many patches ranging in size from large to small, to avoid idiosyncrasies of the species-area relationship when patches are small (Lomolino \& Weiser 2001), few patches are sampled (Triantis et al. 2012), or the range in 
patch sizes is low (Watling \& Donnelly 2006). Here we consider effects of patch size, patch isolation, patch density (number of patches per unit area), and habitat amount on species density to evaluate comprehensively the HAH. Our primary analyses are based on 33 studies in which we differentiated forest inhabitants from habitat generalists $(N=531$ patches and 2061 species). Additional analyses using all species are consistent with the results reported in the main text, and are included as supplementary material.

We tested the following predictions of the HAH (1) habitat amount in the local landscape has a stronger effect on species density than individual effects of either size or isolation of the patch in which the sample plot is contained; (2) habitat amount in the local landscape has at least as strong an effect on species density as the combined effects of the size and isolation of the patch in which the sample plot is contained; (3) patch density in the local landscape has no effect on species density, once the effect of habitat amount is controlled (i.e. no effect of habitat fragmentation per se); and (4) any positive effects of patch size, negative effects of patch isolation, and negative effects of fragmentation per se do not become stronger with declining habitat amount.

\section{MATERIALS AND METHODS}

Our test of the HAH used data on 5675 species from eight major taxonomic groups (plants, fungi, gastropods, insects, amphibians, reptiles, birds and mammals). Species were sampled in plots located in 554 habitat patches (mainly forest) described from 35 studies in South America $(n=14)$, North America $(n=8)$, Europe $(n=4)$, Oceania $(n=4)$, Africa $(n=3)$ and Asia ( $n=2$; Table 1; Fig. S1).

\section{Species data}

We searched the BioFrag database (Pfeifer et al. 2014) for studies reporting species counts in individual plots, considering a 'plot' to be any sample of fixed area, including quadrats, transects or mist net arrays. We required that plots were located in discrete patches that could be detected in satellite images, rather than sampled along habitat gradients, so that we could directly compare effects of patch size, isolation and habitat amount. We obtained data from 20 studies from the BioFrag database. To supplement the BioFrag studies, we surveyed the primary literature in March 2015 using three keyword combination searches in a Web of Science query: ('species richness' and 'plot' and 'fragment'), ('species richness' and 'plot' and 'patch'), ('species richness' and 'plot' and 'island'). We used the same terms to search the online data archives Dryad, Ecological Archives, and the Long-Term Ecological Research network. To include a study in our analysis we required that (1) authors reported species counts on a plot-by-plot basis in habitat patches, or sampled the same number of plots in each patch; (2) reported the area of all sampled patches and (3) included a detailed map or description of the study area from which we could locate individual patches from satellite images. Although 953 studies met our search criteria, most studies of species richness in fragmented landscapes do not represent strong tests of the HAH because they aggregate species counts in patches, rather than

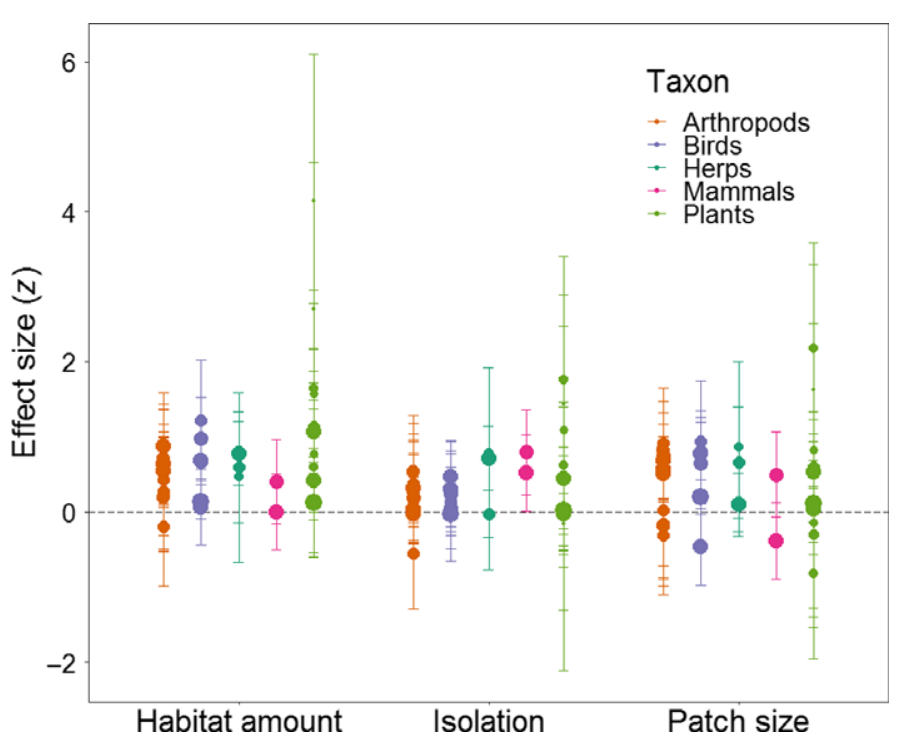

Figure 2 The mean effect size for habitat amount on species density was greater than the mean effect of patch size or isolation in 33 studies of forest species. Here, points indicate effect sizes, and are scaled to be proportional to the number of patches surveyed in each study. Error bars indicate $95 \%$ confidence intervals around the effect sizes estimates.

reporting richness from individual plots. Exclusion criteria for most of the 953 studies are included in Supplemental material and methods. We retained species data from 11 out of 953 literature studies, and added data from four studies conducted by colleagues from whom we could obtain plot-level species counts. Together with the 20 BioFrag studies, we analysed a pool of 35 studies from all continents except Antarctica (Table S1). We estimated species density as the number of species per plot. Although we differentiated forest inhabitants from habitat generalists, and calculated extrapolated species density estimates to account for variation in sampling intensity (described in the supplementary material), we acknowledge that comparisons of species counts such as those reported here may be subject to biases resulting from sampling differences among studies (Gotelli \& Colwell 2001).

\section{Habitat classification}

We acquired Landsat and ALOS-PALSAR satellite images for each study area to create habitat maps. All but one study took place in forest patches, so we created forest/non-forest classifications for 34 studies, and a terrestrial/ocean classification for one island study (Sfenthourakis \& Panitsa 2012). Although 'habitat' may not necessarily be well described by land cover (Betts et al. 2014), given the large number of species and landscapes included in our study, we made the simplifying assumption that forest cover represents habitat in the 34 studies of forest patches. It is likely that the patterns we describe here would be refined with additional site data, for example by differentiating plantations and secondary forest from primary forest. A full description of the protocol for creating and validating forest maps is included in Supplemental material and methods. 
We obtained patch size data from individual studies when available, and from the forest cover maps when unavailable. The cell size of satellite images used to create forest cover maps was $30 \times 30 \mathrm{~m}^{2}$, which means that the smallest patches that could be detected in our maps were 0.09 ha. For all studies, the forest cover map was used to estimate habitat amount, patch density and patch isolation in local landscapes centred on each plot. We lacked coordinate data for the 15 studies obtained from the literature, so for those studies we centred local landscapes on the centroid of individual patches. We used nested circular buffers with six different radii to describe habitat amount in local landscapes surrounding the plots. The radii were 200, 500, 1000, 2000, 3000 and $6000 \mathrm{~m}$ corresponding to local landscapes of approximately 13, 79, 314, 1257, 2827 and 11309 ha. We estimated habitat amount around individual plots, averaging the data by patch in cases where patches contained multiple plots. We used this multiscale approach rather than determining the size of local landscapes a priori on the basis of organism traits such as dispersal capacity because dispersal in a given species can vary with characteristics of the surrounding landscape (Haynes et al. 2007), and adequate data to generate dispersal expectations for the taxa and landscapes represented in our study do not exist. We evaluated three common metrics that include both distance- and area-based measures of patch isolation: nearestneighbour distance, global isolation (the mean distance of the focal patch to all other patches in the local landscape; Viera et al. 2018) and the area-weighted proximity index (the sum of the area of all patches in the local landscape divided by their nearest-neighbour distance; Gustafson \& Parker 1994). We counted the number of forest patches in local landscapes, considering patches to be distinct when separated from one another by at least one non-forest pixel on all sides (including corners). We used the patch counts to calculate patch density (number of patches divided by the area of the local landscape) as a measure of forest fragmentation.

\section{Statistical analyses}

Prediction 1: Habitat amount vs. size and isolation of the patch containing the sample plot

We used meta-analysis, weighted regression and comparisons of slope coefficients to test the first prediction of the HAH. We first compared effect sizes for habitat amount, patch size and patch isolation using meta-analysis. To assess the effect of habitat amount, we calculated $r$ between $\log _{10}$ (habitat amount) and $\log _{10}$ (mean species density) in each of the six local landscape sizes. We retained the local landscape resulting in the largest $r$ as the best estimate of the effect of habitat amount on species density. To describe patch size effects, we calculated Pearson's correlation coefficient $(r)$ for the relationship between $\log _{10}$ (local patch size) and $\log _{10}$ (mean species density) for all patches sampled in each of the 35 studies. For isolation, we calculated $r$ between $\log _{10}$ (mean species density) and each of the three isolation measures in the best-fit local landscapes in which habitat amount was measured. Based on the notion that increasing isolation decreases species richness (MacArthur \& Wilson 1967), we expected that species density would be negatively correlated with nearest-neighbour distance and global isolation, but positively correlated with the proximity index. We selected the isolation metric for each study that best met this expectation. When at least one of the metrics was in the expected direction (negative for the first two measures, and positive for the third), we retained the one with the largest absolute value in the expected direction. When none of the metrics was in the expected direction, we selected the one with the lowest absolute value. To make the isolation data comparable with the patch and habitat amount data, we recoded signs for the correlation retained in each study as positive when the metric was in the expected direction, and negative when it was not. All $r$ values were transformed to effect size estimates for habitat amount $\left(z_{h a}\right)$, patch size $\left(z_{p s}\right)$ and patch isolation $\left(z_{p i}\right)$ as described in the Supplemental material and methods.

The HAH predicts greater effects of habitat amount than patch size, except where a single patch comprises all of the habitat in a local landscape. In that case, patch size and habitat amount effects are equivalent. We evaluated whether habitat amount and patch size effects converged as habitat amount became dominated by the single local patch containing the sample plot by calculating the 'net patch effect' (NPE) as $z_{p s}-z_{h a}$. We used weighted regression to test whether NPE increased linearly as the mean proportion of habitat amount represented by the local patch increased, weighting each study by the reciprocal of its variance (see Supplemental material and methods).

As a further test of the relative importance of habitat amount, patch size and isolation, we compared 95\% CIs around slope coefficients of the relationship between species density and each of the three variables. If habitat amount is the primary determinant of species density, standardised slopes of the species density - habitat amount relationship should be larger than slopes of either of the species density patch relationships, and have $95 \%$ CIs that both exclude zero and the $95 \%$ CIs of the other relationships. We calculated slope coefficients and 95\% CIs using maximum likelihood estimation of generalised least-square regression models with standardised predictor variables and an exponential spatial correlation matrix to account for spatial autocorrelation in the species density data (Dormann et al. 2007). We compared eight models, one each for the effects of patch size and isolation on species density, and one for the effect of habitat amount in each of six local landscapes. Because we compared multiple measures of habitat amount, we calculated Bonferroni-corrected $95 \%$ CIs for all models, and used $z$-tests to compare the proportion of studies consistent with the HAH vs. those reporting larger slopes for patch effects.

Prediction 2: Habitat amount vs. the combined effects of size and isolation of the patch containing the sample plot

The HAH predicts that models including only habitat amount should result in a more plausible fit to the species density data than models including both patch size and isolation. We used evidence ratios based on corrected Akaike's information criterion $\left(\mathrm{AIC}_{\mathrm{c}}\right)$ scores to compare three models: (1) patch size + isolation, (2) habitat amount only and (3) a null (intercept only) model. All models were fit using maximum likelihood estimation of a generalised least-square model, with 
standardised predictors and an exponential spatial correlation matrix. We calculated the likelihood of each model being the most plausible among those compared as $\frac{\exp \left(-0.5_{i}\right)}{\sum_{i=1}^{p} \exp \left(-0.5_{i}\right)}$ (Anderson 2008), and then calculated the evidence ratio as the likelihood of the habitat amount model divided by the likelihood of model with patch size + isolation. We report the mean evidence ratio for the habitat amount models, using all studies in which variance inflation factors (VIFs) for models including habitat amount and patch variables were less than 5 (Hair et al. 2006).

\section{Prediction 3: Habitat fragmentation per se}

We used evidence ratios derived from a second model comparison to test for effects of fragmentation in local landscapes on species density, after accounting for habitat amount. We compared three models: one with habitat amount, one including both habitat amount and patch density, and a null (intercept only) model. If habitat fragmentation has a significant independent effect on species density, a model including both terms should provide a more plausible fit to the species data than a model including only habitat amount. We used standardised predictors, excluded studies in which full models had VIFs $>5$, and differentiated cases where the best-fit model was not significantly different from a null model.

Prediction 4: Effects of patch size or patch isolation with declining habitat amount

Finally, we tested for significant interactions between habitat amount and either patch size or patch isolation. We used pseudo-quasi-likelihood generalised linear mixed effects models fit with a Gaussian error distribution, and included an exponential spatial correlation matrix to account for spatial autocorrelation in the species density data. Taxonomic group was included as a fixed effect, and study was coded as a random effect. We removed studies in which VIFs $>5$.

All spatial and statistical analyses were conducted in $\mathrm{R}(\mathrm{R}$ Development Core Team 2018). For predictions 2-4 we inspected quantile plots to confirm that models residuals were generally normally distributed.

\section{RESULTS}

Prediction 1: Habitat amount vs. size and isolation of the patch containing the sample plot

A consistent effect of habitat amount was apparent via metaanalysis, comparison of slope coefficients and model selection. Across all studies, the habitat amount effect size was usually positive (31/33 effects, $91 \%$ of studies), the patch size effect was positive $73 \%$ of studies, and the patch isolation effect was in the expected direction in $82 \%$ of studies. The local landscape size at which habitat amount was maximised was relatively evenly distributed among landscape sizes, with 8,6 , 7, 4, 2 and 8 studies each in local landscapes of $\sim 13,79,314$, 1257, 2827 and 11309 ha. The best-fit isolation metric was the proximity index in $70 \%$ of studies $(23 / 33)$, with nearestneighbour distance and global isolation most correlated with species density in five studies each.
As predicted by the $\mathrm{HAH}$, the mean effect size of habitat amount $(0.606 \pm 0.007)$ was significantly larger than the mean effect of patch size $(0.351 \pm 0.007)$ or isolation $(0.287 \pm 0.007$; $Q=7.56, P=0.006$; Fig. 2, Fig. S2). The net patch effect (NPE) was negative in 24 of 33 studies $(73 \%)$ resulting in negative mean $(-0.39)$ and median $(-0.20)$ NPEs. As predicted by the HAH, NPEs increased towards zero as local patches occupied a larger proportion of the habitat in local landscapes $\left(F_{1,31}=8.54, P=0.006, R_{\text {adj }}^{2}=0.19 ;\right.$ Fig. 3$)$. Additional analyses using estimated species density to account for sampling effects, and data on all species (not just forest inhabitants), were qualitatively consistent with these findings (Table S2).

The $95 \%$ CIs around the slope estimates for the relationship between species density and habitat amount excluded zero more frequently than for relationships between species density and patch size or isolation, although the result was not statistically significant $\left(\chi^{2}=1.28, P=0.129 ; N=33\right)$. There were six studies in which the Bonferroni-corrected $95 \%$ CIs around the slope estimate for habitat amount excluded zero but the patch CIs included zero, and two studies in which the habitat amount CIs included zero but at least one of the patch CIs did not (Fig. S3). Similar results were apparent using estimated species density data for forest inhabitants (Fig. S4), data for all species (Fig. S5), and estimated density data for all species (Fig. S6).

\section{Prediction 2: Habitat amount vs. the combined effects of size and isolation of the patch containing the sample plot}

Seven studies had VIFs $>5$ and were excluded from consideration. Of the remaining 26 studies, a model including only habitat amount was, on average, over 60 times more likely to provide the most plausible fit to the species density data than a

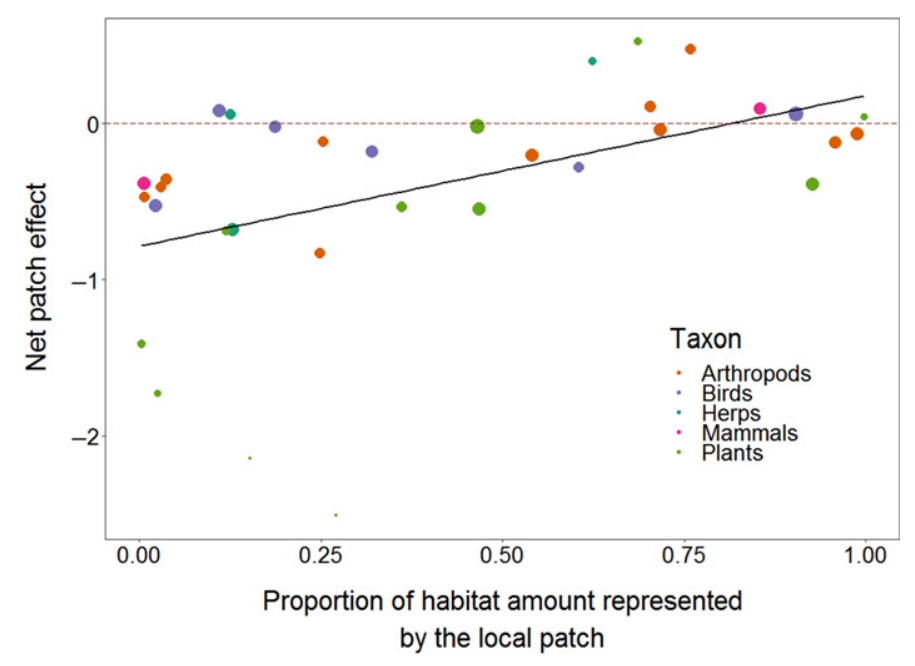

Figure 3 The net patch effect (patch size effect - habitat amount effect) was negative in most of the 33 studies, indicating that patch size effects were generally smaller than habitat amount effects, but increased as habitat in local landscapes became increasingly represented by the patch in which species data were collected (the local patch). The size of each point is proportional to the number of patches surveyed in the study. 
model with the two patch characteristics (Fig. 4a; Table S3; note that our assessment of evidence ratios does not include two studies in which the evidence ratio for the habitat amount model was over 200 000). Excluding studies for which the most plausible model was not significantly better than a null model did not appreciably alter that result. Models including only a habitat amount term consistently provided the most plausible fit to the different measures of species density than models including both patch size and isolation (Tables S4-S6).

\section{Prediction 3: Habitat fragmentation per se}

Excluding six studies with VIFs $>5$ and another 16 studies in which the selected model was not significantly different from null, a model including only habitat amount was, on average over 40 times more likely to provide the most plausible fit to the species data than a model of fragmentation per se. As before, including all studies did not substantially change this result (Fig. 4b; Table S7; our mean evidence ratio did not include one study supporting the habitat amount only model with an evidence ratio over 500 000). The direction of the fragmentation effect, controlling for habitat amount, was positive in all but two of the studies included. Similar results were seen for the additional partitions of the species data (Tables S8-S10).

\section{Prediction 4: Interactions between habitat amount and patch size or patch isolation}

Mixed models including a random effect of study and accounting for spatial autocorrelation in the density of forest species revealed no significant interaction between habitat amount and patch size, patch isolation or patch density (all $P>0.69$; Table 1).
Table 1 Non-significant interactions from linear mixed effects models indicated that effects of patch size, patch isolation and patch density (fragmentation per se) in local landscapes did not vary with habitat amount

\begin{tabular}{lcrrr}
\hline Model & B & SE & \multicolumn{1}{c}{$P$} & $R^{2}$ \\
\hline Habitat amount \& patch size & & & & 0.74 \\
Intercept & 1.10 & 0.12 & $<0.001$ & \\
Patch size & 0.01 & 0.02 & 0.600 & \\
Habitat amount & 0.29 & 0.10 & 0.005 & \\
Patch size $\times$ habitat amount & -0.007 & 0.04 & 0.866 & \\
Habitat amount \& patch isolation & & & & 0.69 \\
Intercept & 0.97 & 0.12 & $<0.001$ & \\
Patch isolation & 0.05 & 0.01 & 0.002 & \\
Habitat amount & 0.31 & 0.12 & 0.009 & \\
Patch isolation $\times$ habitat amount & -0.03 & 0.02 & 0.271 & \\
Habitat amount \& fragmentation per se & & & & 0.70 \\
Intercept & 1.08 & 0.12 & $<0.001$ & \\
Fragmentation per se & 0.14 & 0.17 & 0.418 & \\
Habitat amount & 0.32 & 0.07 & $<0.001$ & \\
Fragmentation per se $\times$ habitat amount & -0.06 & 0.448 & 0.897 & \\
\hline
\end{tabular}

\section{DISCUSSION}

Our results support the habitat amount hypothesis (HAH). The effect of habitat amount on species richness around sample plots is stronger than either the individual or combined effects of patch size and isolation. Patch size is important for species richness in plots because it contributes to habitat amount in local landscapes. When all the habitat in a local landscape is represented by a single patch, the patch size and habitat amount effect sizes are similar. However, the importance of patch size decreases as the patch containing a sample plot contributes less to habitat amount. Large patches are important for species density because they contribute to high habitat amount, but they are no more important than a
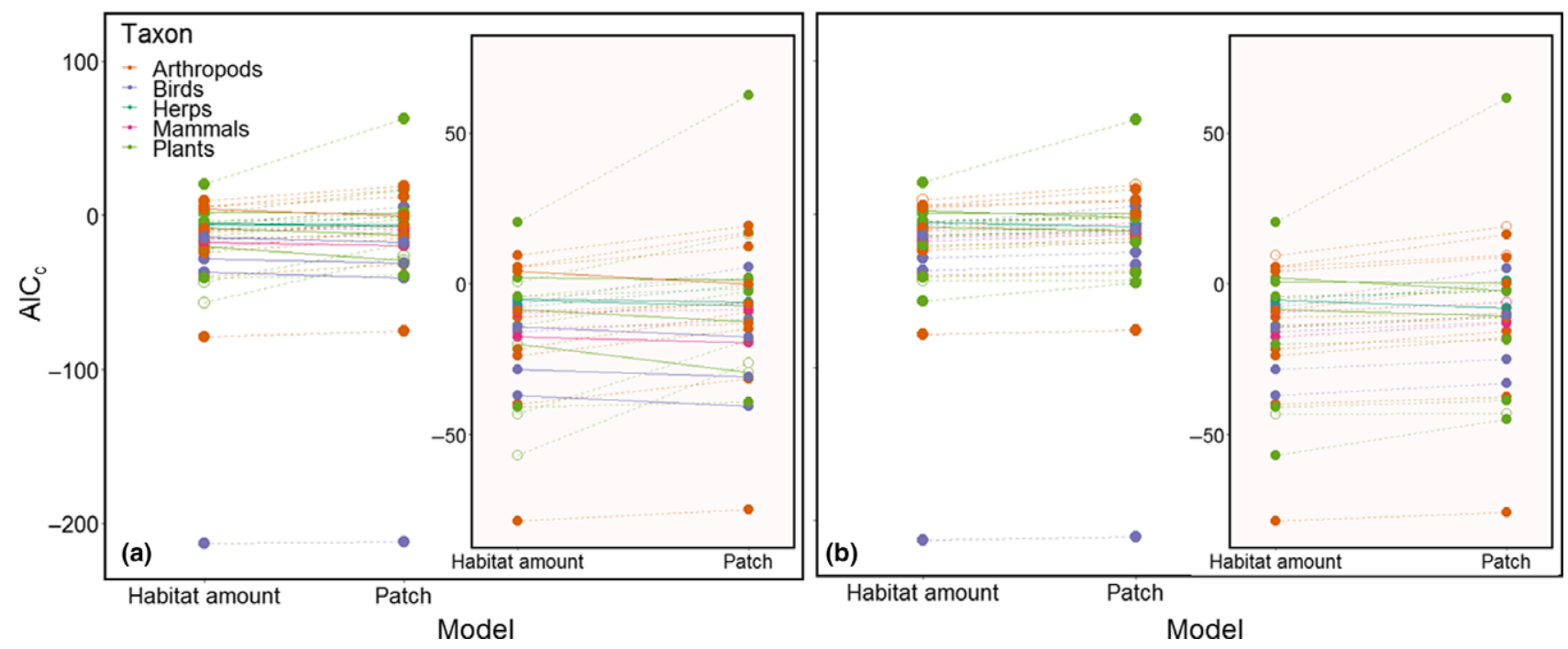

Figure 4 Regression models containing only a term for habitat amount usually provided a better fit to the species density data than (a) models including patch area and isolation or (b) models of fragmentation per se (habitat amount and patch density). Both panels compare corrected Akaike's information criterion $\left(\mathrm{AIC}_{\mathrm{c}}\right)$ scores for each study. Lower $\mathrm{AIC}_{\mathrm{c}}$ scores indicate better fit to the species data. Studies connected by dashed lines indicate that $\mathrm{AIC}$ for the model with habitat amount only was lower than $\mathrm{AIC}_{\mathrm{c}}$ for the model including patch characteristics, whereas solid lines indicate the opposite. The inset in each panel highlights results for all studies with $\mathrm{AIC}_{\mathrm{c}}>-100$. In panel (a), open circles indicate studies in which variance inflation factors $>5$. In panel (b), studies in which the effect of fragmentation was positive (patch density was positively correlated with species density) are indicated as filled circles, whereas open circles indicate studies with a negative fragmentation effect. 
collection of multiple patches summing the same total area in local landscapes around sample plots. Distance is important because it defines the scale of effect at which habitat amount is measured. But within local landscapes, distance-based isolation is usually not a major determinant of species density. Note that the predictions of the $\mathrm{HAH}$, and results described here, hold at the scale of clearly defined local landscapes (here ranging in size from about 13-11,000 ha) around survey plots, but do not necessarily extrapolate to larger, amorphously defined and unbounded concepts of a generalised 'landscape'.

We found no evidence for consistent negative effects of fragmentation per se on species density. Fragmentation per se was not included in the most plausible model of species density in over $85 \%$ of studies examined ( 29 out of 33 studies). In all four studies with a detectable effect of fragmentation per se on species density, this effect was positive (Studies 12, 14 and 15, all on plants in the Atlantic Forest of Brazil, and Study 24 on amphibians and reptiles in Mexico). This result is broadly consistent with a review of responses to fragmentation per se (Fahrig 2017). Although we lack data from which we can infer the mechanism(s) underlying these responses to fragmentation per se, many possibilities exist (see fig. 3 in Fahrig et al. 2019), including positive or negative edge effects, reduced or enhanced movement success, and reduced risk from spatially autocorrelated disturbances. However, given that fragmentation per se was only rarely included in selected models, it appears that such mechanisms usually do not have strong effects on the number of species in sample plots. Our results underscore the value of the HAH as a null model against which habitat fragmentation mechanisms (Fletcher et al. 2018) can be compared. Studies should first control for habitat amount before invoking alternative mechanisms to explain changes in species density in fragmented landscapes (Fahrig 2003).

Although habitat amount usually outperformed patch area and isolation variables, there were cases where the opposite was true. In six studies, the combination of patch variables was significantly different from a null model, and provided a more plausible fit to the species density data than habitat amount alone. The degree of support for the patch model in those studies was modest, suggesting relatively little difference between the patch and habitat amount models. Importantly, the isolation metric selected in those studies was the proximity index, a hybrid areabased isolation metric that sums the area of patches in the local landscape divided by their nearest-neighbour distance (Gustafson \& Parker 1994). The proximity index was identified as the best isolation metric in two-thirds of studies overall, highlighting the importance of area-based isolation measures in general. That being the case, the 'exceptions' to the HAH we identified are not particularly surprising, given that we would expect little difference between patch and habitat amount models when area-based isolation measures are used.

We acknowledge two limitations to our methods, and a caveat. First, our estimates of forest cover, although validated when possible, are subject to classification error. Furthermore, equating forest cover with habitat, even for forest-dwelling species, is an oversimplification. Many forest species are limited by the availability of specialised reproductive habitats (Zimmerman \& Bierregaard 1986) or patchily distributed keystone structures (Manning et al. 2006) that may limit their distribution in forest. Second, some study regions may have been subject to anthropogenic disturbance for so long that assemblages are depauperate in species with large patch size requirements. The loss of species from regions may have homogenised communities to the point that we cannot statistically differentiate between effects of patch characteristics and habitat amount. Finally, we reiterate that the response variable we measured was species density, an aggregate measure which may obscure the decline of individual species that are sensitive to environmental changes in fragmented landscapes.

Humans have modified over $40 \%$ of the Earth's terrestrial land area (Barnosky et al. 2012), making it ever more important to identify pragmatic conservation actions that mitigate biodiversity loss. The HAH implies that to maintain species density (alpha diversity), all habitat is valuable for conservation, irrespective of whether it occurs in a small or isolated patch. Conservation strategies such as habitat restoration (Bernal et al. 2018) and payment for ecosystem services that offer benefits only to landowners preserving large patches undermine the economic and ecological cumulative value of small habitat patches (Banks-Leite et al. 2012; HernándezRuedas et al. 2014). Preserving and restoring as much habitat as possible is the best way to minimise species losses.

\section{ACKNOWLEDGEMENTS}

We thank Sebastian Ortiz for assisting with the compilation of literature data, and Rob Ewers, Charlotte Owen and Anna Pidgeon for making survey data available through the BioFrag network. Yrjo Haila, David Jenkins and two anonymous reviewers provided valuable comments that helped improve the manuscript.

\section{AUTHORSHIP}

JIW, VA-R and LF conceived the study, all authors collected data, JIW and RF analysed data, JIW wrote the original draft, and all authors reviewed and edited the manuscript.

\section{AUTHORS' CONTRIBUTIONS}

Conceptualization: J. I. W., V. A-R. and L. F.; Data curation: J. I. W.; Formal analysis: J. I. W.; Investigation: all authors; Methodology: J. I. W., V. A-R., L. F.; Visualization: J. I. W., V. A-R., L. F.; Writing - original draft: J. I. W.; Writing review \& editing: all authors.

\section{COMPETING INTERESTS}

Authors declare no competing interests.

\section{FUNDING INFORMATION}

V. A.-R. was supported by CONACyT grant 2015-253946.

\section{DATA AND MATERIALS AVAILABILITY}

Survey data from BIOFrag studies are available through the BioFrag website. Data tables and $\mathrm{R}$ code for analyses 
reported on here will be submitted to the Dryad Digital Repository upon acceptance of this manuscript.

\section{DATA AVAILABILITY STATEMENT}

Data available from the Dryad Digital Repository: https:// doi.org/10.5061/dryad.fbg79cnrj.

\section{REFERENCES}

Anderson, D.R. (2008). Model Based Inference in the Life Sciences. Springer, New York, NY.

Banks-Leite, C., Ewers, R.M. \& Metzger, J.P. (2012). Unraveling the drivers of community dissimilarity and species extinction in fragmented landscapes. Ecology, 93, 2560-2569.

Barnosky, A.D., Hadly, E.A., Bascompte, J., Berlow, E.L., Brown, J.H., Fortelius, M. et al. (2012). Approaching a state shift in Earth's biosphere. Nature, 486, 52-58.

Bernal, B., Murray, L.T. \& Pearson, R.H. (2018). Global carbon dioxide removal rates from forest landscape restoration activities. Carbon Balance Manage, 13, 22.

Betts, M.G., Fahrig, L., Hadley, A.S., Halstead, K.E., Bowman, J., Robinson, W.D. et al. (2014). A species-centered approach for uncovering generalities in organism responses to habitat loss and fragmentation. Ecography, 37, 517-527.

Dormann, C.F., McPherson, J.M., Araújo, M.B., Bivand, R., Bolliger, J., Gudrun, C. et al. (2007). Methods to account for spatial autocorrelation in the analysis of species distributional data: a review. Ecography, 30, 609-628.

Fahrig, L. (2003). Effects of habitat fragmentation on biodiversity. Annu. Rev. Ecol. Evol. Syst., 34, 487-515.

Fahrig, L. (2013). Rethinking patch size and isolation effects: the habitat amount hypothesis. J. Biogeogr., 40, 1649-1663.

Fahrig, L. (2017). Ecological responses to habitat fragmentation per se. Ann. Rev. Ecol. Evol. Syst., 48, 1-23.

Fahrig, L., Arroyo-Rodríguez, V., Bennett, J.R., Boucher-Lalonde, V., Cazetta, E., Currie, D.J. et al. (2019). Is habitat fragmentation bad for biodiversity? Biol. Conserv., 230, 179-186.

Fletcher, R.J., Didham, R.K., Banks-Leite, C., Barlow, J., Ewers, R.M., Rosindell, J. et al. (2018). Is habitat fragmentation good for biodiversity? Biol. Conserv., 226, 9-15.

Gotelli, N.J. \& Colwell, R.K. (2001). Quantifying biodiversity: procedures and pitfalls in the measurement and comparison of species richness. Ecol. Lett., 4, 379-391.

Gustafson, E.J. \& Parker, G.R. (1994). Using an index of habitat patch ptroximity for landscape design. Landscape Urban Plan., 29, 117-130.

Haddad, N.M., Gonzalez, A., Brudvig, L.A., Burt, M.A., Levey, D.J. \& Damschen, E.I. (2017). Experimental evidence does not support the Habitat Amount Hypothesis. Ecography, 40, 48-55.

Hair, J.F., Anderson, R., Tatham, R.L. \& Black, W.C. (2006). Multivariate Data Analysis. Prentice Hall, Upper Saddle River, NJ.

Hanski, I. (1994). A practical model of metapopulation dynamics. $J$. Animal. Ecol., 63, 151-162.

Hanski, I. (2015). Habitat fragmentation and species richness. $J$. Biogeogr., 42, 989-993.

Haynes, K.J., Dillemuth, F.P., Anderson, B.J., Hakes, A.S., Jackson, H.B., Jackson, S.E. et al. (2007). Landscape context outweighs local habitat quality in its effect on herbivore dispersal and distribution. Oecologia, 151, 431-441.

Hernández-Ruedas, M.A., Arroyo-Rodríguez, V., Maeve, J.A., MartínezRamos, M., Ibarra-Manríquez, G., Martínez, E. et al. (2014). Conserving tropical tree diversity and forest structure: the value of small rainforest patches in moderately-managed landscapes. PLoS ONE, 9, e98931.

Lindenmayer, D. \& Fischer, J. (2007). Tackling the habitat fragmentation panchreston. Trends Ecol. Evol., 22, 127-132.
Lomolino, M.V. \& Weiser, M.D. (2001). Towards a more general speciesarea relationship: diversity on all islands, great and small. J. Biogeogr., 28, 431-445.

MacArthur, R.H. \& Wilson, E.O. (1967). The Theory of Island Biogeography. Princeton University Press, Princeton, NJ.

Manning, A.D., Fischer, J. \& Lindenmayer, D.B. (2006). Scattered trees are keystone structures - implications for conservation. Biol. Conserv., 132, 311-321.

Martin, C. (2018). An early synthesis of the habitat amount hypothesis. Landscape Ecol., 33, 1831-1835.

Martin, A.E. \& Fahrig, L. (2012). Measuring and selecting scales of effect for landscape predictors in species-habitat models. Ecol. Appl., 22, 2277-2292.

Matthews, T.J., Triantis, K.A., Rigal, F., Borregaard, M.K., Guilhaumon, F. \& Whittaker, R.J. (2016). Island species-area relationships and species accumulation curves are not equaivalent: an analysis of habitat island datasets. Global Ecol. Biogeogr., 25, 607-618.

Melo, G.L., Sponchiado, J., Cáceres, N.C. \& Fahrig, L. (2017). Testing the habitat amount hypothesis for South American small mammals. Biol. Conserv., 209, 304-314

Pfeifer, M., Lefebvre, V., Gardner, T.A., Arroyo-Rodríguez, V., Baeten, L., Banks-Leite, C. et al. (2014). BIOFRAG - a new database for analyzing BIOdiversity responses to FRAGmentation. Ecol. Evol., 4, 1524-1537.

Pfeifer, M., Lefebvre, V., Peres, C.A., Banks-Leite, C., Wearn, O.R., Marsh, C.J. et al. (2017). Creation of forest edges has a global impact on forest vertebrates. Nature, 551, 187-191.

Prugh, L.R. (2009). An evaluation of patch connectivity measures. Ecol. Appl., 19, 1300-1310.

R Development Core Team (2018). R: A language and environment for statistical computing. R Foundation for Statistical Computing, Vienna, Austria. Available at: http://wwwr-project.org. Last accessed 18 May 2018.

Saldhana Bueno, A. \& Peres, C.A. (2019). Patch-scale biodiversity retention in fragmented landscapes: reconciling the habitat amount hypothesis with the island biogeography theory. J. Biogeogr., 46, 621-632.

Sfenthourakis, S. \& Panitsa, M. (2012). From plots to islands: species diversity at different scales. J. Biogeogr., 39, 750-759.

Taubert, F., Fischer, R., Groeneveld, J., Lehmann, S., Müller, M.S., Rödif, E. et al. (2018). Global patterns of tropical forest fragmentation. Nature, 554, 519-522.

Triantis, K.A., Guilhaumon, F. \& Whittaker, R.J. (2012). The island species-area relationship: biology and statistics. J. Biogeogr., 39, 215-231.

Viera, M., Almeida-Gomes, M., Delciellos, A.C., Cerqueira, R. \& Crouzeilles, R. (2018). Fair tests of the habitat amount hypothesis require appropriate metrics of patch isolation: an example with small mammals in the Brazilian Atlantic Forest. Biol. Conserv., 226, 264-270.

Watling, J.I. \& Donnelly, M.A. (2006). Fragments as islands: a synthesis of faunal responses to habitat patchiness. Conserv. Biol., 20, 1016-1025.

Weigelt, P. \& Kreft, H. (2013). Quantifying island isolation - insights from global patterns of insular plant species richness. Ecography, 36, 417-429.

Zimmerman, B.L. \& Bierregaard, R.O. (1986). Relevance of the equilibrium theory of island biogepgrahy and species-area relations to conservation with a case from Amazonia. J. Biogeogr., 13, 133-143.

\section{SUPPORTING INFORMATION}

Additional supporting information may be found online in the Supporting Information section at the end of the article.

Editor, David Storch

Manuscript received 5 August 2019

First decision made 18 September 2019

Second decision made 23 December 2019

Manuscript accepted 14 January 2020 